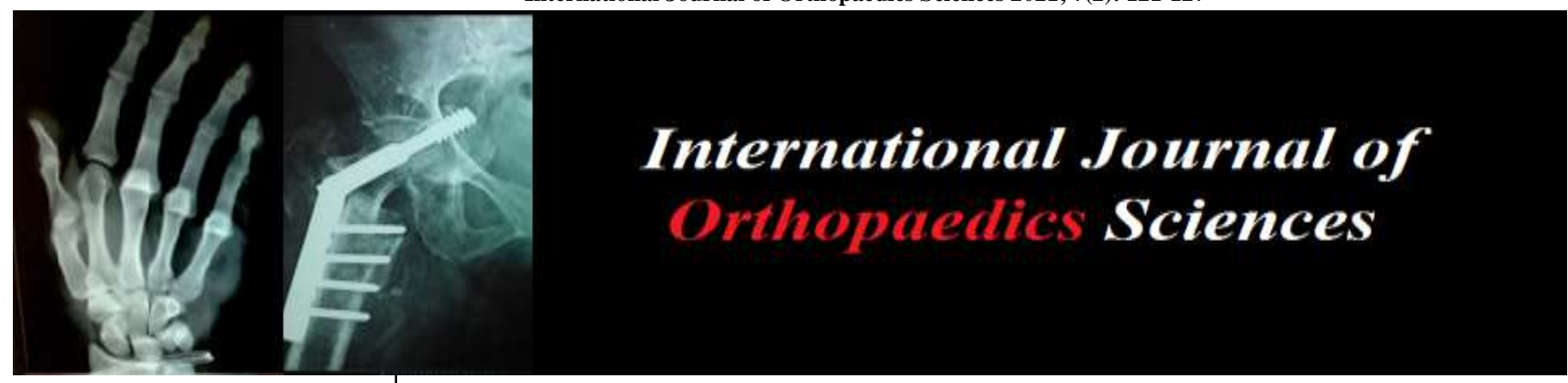

E-ISSN: 2395-1958

P-ISSN: 2706-6630

IJOS 2021; 7(2): 121-127

(C) $2021 \mathrm{IJOS}$

www.orthopaper.com

Received: 23-02-2021

Accepted: 25-03-2021

Dr. Madan Mohan Ballal Professor in Orthopaedics, Sanjay Gandhi Institute of Trauma and Orthopaedics,

Bangalore, Karnataka, India

Dr. Chidananda KJC

Associate Professor in Orthopaedics, Sanjay Gandhi

Institute of Trauma and

Orthopaedics, Bangalore,

Karnataka, India

Dr. Muthu Kishore M Junior Resident in Orthopaedics,

Sanjay Gandhi Institute of

Trauma and Orthopaedics,

Bangalore, Karnataka, India

Dr. Nagegowda KN

Junior Resident in Orthopaedics,

Sanjay Gandhi Institute of

Trauma and Orthopaedics,

Bangalore, Karnataka, India

\section{Functional outcome of open latarjet procedure for recurrent anterior shoulder instability: A prospective study}

\author{
Dr. Madan Mohan Ballal, Dr. Chidananda KJC and Dr. Muthu Kishore \\ $M$ and Dr. Nagegowda KN
}

DOI: $\underline{\text { https://doi.org/10.22271/ortho.2021.v7.i2b.2622 }}$

\begin{abstract}
Introduction: Shoulder joint owing to its anatomy and biomechanics is the most unstable and frequently dislocated joint in our body. Anterior shoulder instability is often caused by glenoid and/or humeral bony defects in addition to soft tissue injuries. Most commonly seen in young and athletic population with high demand activities. Arthroscopic Bankart repair and open Latarjet procedure are the mainstay of treatment for recurrent anterior shoulder instability. Here we analyse the functional outcome of the shoulder joint repair following Open Latarjet procedure for recurrent anterior shoulder instability.

Methods: Prospective study conducted for 2 years among 34 patients who met our criteria for open Latarjet procedure. In which coracoid process along with the conjoint tendon is transferred and fixed with non-absorbable to the margin of glenoid. This procedure provides stability by bony effect, Bankart effect and dynamic sling effect. Phased Rehabilitation was customised based on tissue quality, stability of repair. Outcome was assessed with ISIS score (Injury Severity Index Score), Rowe score, quick DASH (The Disabilities of Arm, Shoulder and Hand) score, ASES score (The American Shoulder and Elbow Surgeons Shoulder Score) and Visual analogue scale.

Results: Follow up done at 2 weeks, 1 month, 3 month and 6 month showed progressive improvement in Range of motions, Apprehension relief, pain relief, return to normal activities and no any recurrence of instability and improved assessment scores.

Conclusion: For recurrent anterior shoulder instability Open Latarjet procedure showed satisfactory result in terms of stability and range of motion mainly with significant bony defect of glenoid.
\end{abstract}

Keywords: Anterior shoulder instability, open latarjet procedure, glenoid bone loss, rowe score, quick DASH score, ASES score

\section{Introduction}

Shoulder joint is a totally unconstrained joint and allows the greatest range of motion of any articulation in the body added to this, glenohumeral joint is used as a stable fulcrum for placing the upper extremity at various positions in three dimensional spaces. Shoulder by virtue of this special anatomy and biomechanics, is the most unstable and frequently dislocated joint in our body. Accounting for nearly $50 \%$ of all dislocations, with a $2 \%$ incidence in the general population ${ }^{[1,2]}$

Most common type is anterior instability with most common cause is trauma and is often caused by glenoid and/or humeral bony defects additional to soft tissue injuries ${ }^{[3-5]}$. Anterior glenohumeral instability is a common problem in the young, athletic population involving in recreational and sporting activities with rates as high as 12 dislocations per 100,000 exposures $[6,7]$

Arthroscopic Bankart repair and the Open Latarjet procedure are widely considered mainstays of surgical treatment of recurrent anterior shoulder instability ${ }^{[8]}$. Compared to Bankart procedure, the results of Latarjet procedure - first described in 1954 are satisfactory in terms of stability and range of motion for patients with chronic shoulder instability ${ }^{[9]}$. However, most arthroscopic Latarjet techniques do not include a separate capsular reconstruction, in contrast to the open Latarjet procedure [10]. And there is less chances of graft resorption and requires significant longer surgery time in arthroscopic than the open procedure ${ }^{[11]}$.
Corresponding Author: Dr. Muthu Kishore M Junior Resident in Orthopaedics, Sanjay Gandhi Institute of Trauma and Orthopaedics, Bangalore, Karnataka, India 
Open Latarjet procedure can successfully restore shoulder stability in joint with a significant bony defect of glenoid. It's effective in situations in which soft tissue reconstruction is not a reasonable option ${ }^{[12]}$. The purpose of the study is to assess the functional outcome of the anterior shoulder instability following the Open Latarjet procedure in terms of range of motion, apprehension and pain relief, return to normal activities and any recurrences.

\section{Materials and method}

This is a prospective study among patients admitted with anterior shoulder dislocations to Sanjay Gandhi Institute of Trauma and Orthopaedics, Bengaluru during the course of study - November 2018 to September 2020.

\section{Inclusion criteria}

1. Bony Bankart's lesion representing $\geq 25 \%$ of glenoid lesion

2. Hill Sacs lesion

a. On track lesion with glenoid bone loss of $\geq 25 \%$

b. Off track lesion with glenoid bone loss $<25 \%$.

c. Lesions requiring Remplisage correction along with Latarjet procedure.

3. Poor economic status

4. Patients of age group $>18$ years of age.

5. Ability to understand the content of the subject information/informed consent form and willing to participate in the clinical investigation.

\section{Exclusion criteria}

1. Posterior instability of shoulder

2. Any anterior dislocation along with any associated fracture

3. Recurrent anterior instability associated with irreparable rotator cuff lesions.

4. Voluntary anterior dislocators or subluxators

5. Patients with uncontrolled epilepsy

6. Prosthetic anterior instability

7. Connective tissue disorders such as Ehlers-Danlos, Marfans syndrome.

After obtaining institutional ethical committee clearance and written informed consent, patients were taken into the study who met our criteria. Functional scoring of the patient was determined by ASES (The American Shoulder and Elbow Surgeons) score, Quick DASH (The Disabilities of Arm, Shoulder and Hand) score, Rowe score, ISIS (Injury Severity Index Score score) and Visual analogue scale (VAS) for pain to get a baseline reference ${ }^{[13]}$. The case was treated with open Latarjet repair after the criteria were met. In which coracoid process along with the conjoint tendon is transferred and fixed with screws to the margin of glenoid (figures 1-3). This procedure provides stability by Bony effect, Bankart effect and dynamic sling effect. Rehabilitation is always customised based on the tissue quality, stability of the repair. Phased rehabilitation is followed ${ }^{[14]}$. Follow up scores will be taken at weeks 2,1-month,3 months and 6 months to assess functional outcome of the repair. Results were analysed and interpreted using appropriate statistical analysis by using SPSS software.

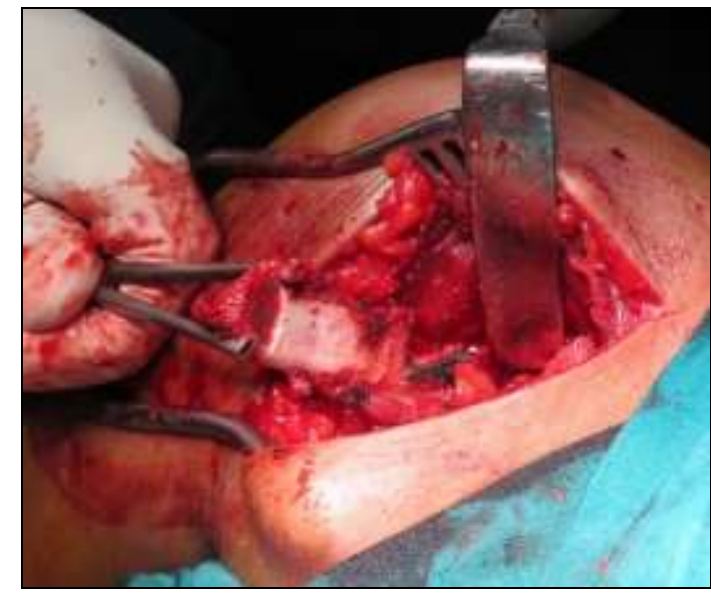

Fig 1: Decortication of the Coracoid

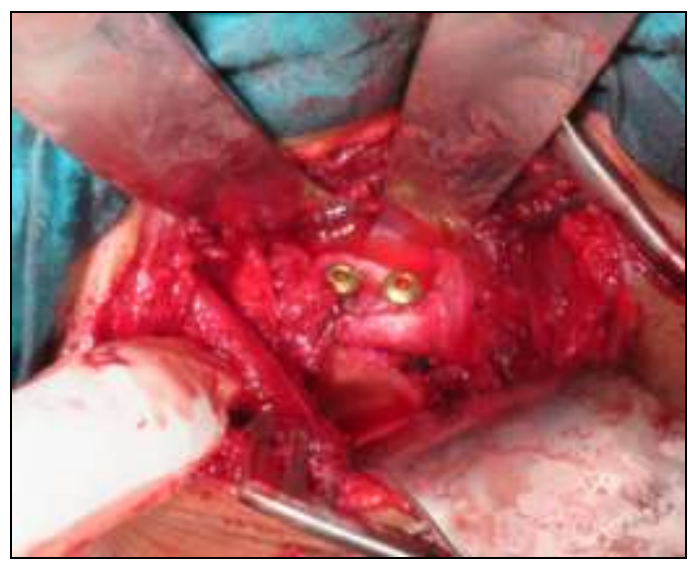

Fig 2: Coracoid graft fixed to the glenoid

\section{Results}

A total of 34 patients were evaluated in the study whose mean age was $33.59(+/-8.27)$ years. 13 patients were less than 30 years $(38.2 \%)$; 19 were between $30-45$ years $(55.9 \%)$ who were the majority and 2 were above 45 years $(5.9 \%)$ (figure 4). All the patients in my study were males except for a lone female. Of total 34 patients 33 were male $(97.1 \%)$ with a female (2.9\%). Among 34 patients, 21(61.8\%) patients had their dominant shoulder affected and remaining 13 (38.2\%) had recurrent instability in their non-dominant shoulder. The majority of the patients were involved in some form of sports activity with 13 patients $(38.2 \%)$ playing contact sports (mostly kabaddi) and 14 patients $(41.2 \%)$ playing recreational sports (badminton, volleyball, cricket). 7 patients $(20.6 \%)$ had no history of any sporting activity. Majority of the patients in the study had a minimum of 5 dislocations prior (N-9, $26.5 \%$ ); Ranging from minimum of one to maximum of ten dislocations prior. With $3(8.8 \%), 2(5.9 \%), 6(17.6 \%), 6$ (17.6\%), 3 (8.8\%), 3 (8.8\%), $2(5.9 \%)$ patients having had 1 , 2, 3, 4, 6, 7 and 10 dislocations prior to reporting respectively. Pre-operative Injury Severity Index Score (ISIS) of the patients were determined. It was found that mean preoperative ISIS score was 3.91. 1 (2.94\%), 14 (41.17\%), 10 (29.41\%), 5 (14.71\%), 4 (11.76\%) patients had an ISIS score of $2,3,4,5$, and 6 respectively. An ISIS score of $<3,3-6$ and $>6$ predicts a recurrence rate of $5 \%, 10 \%$, and $70 \%$, respectively. 


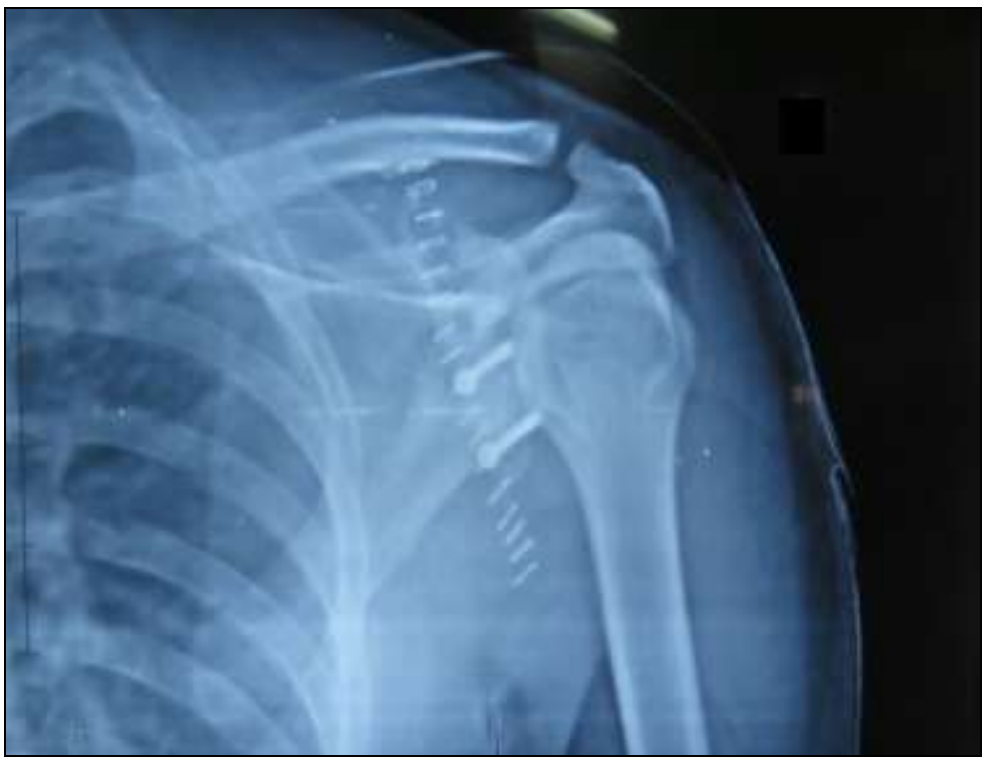

Fig 3: Radiograph - immediate post-op

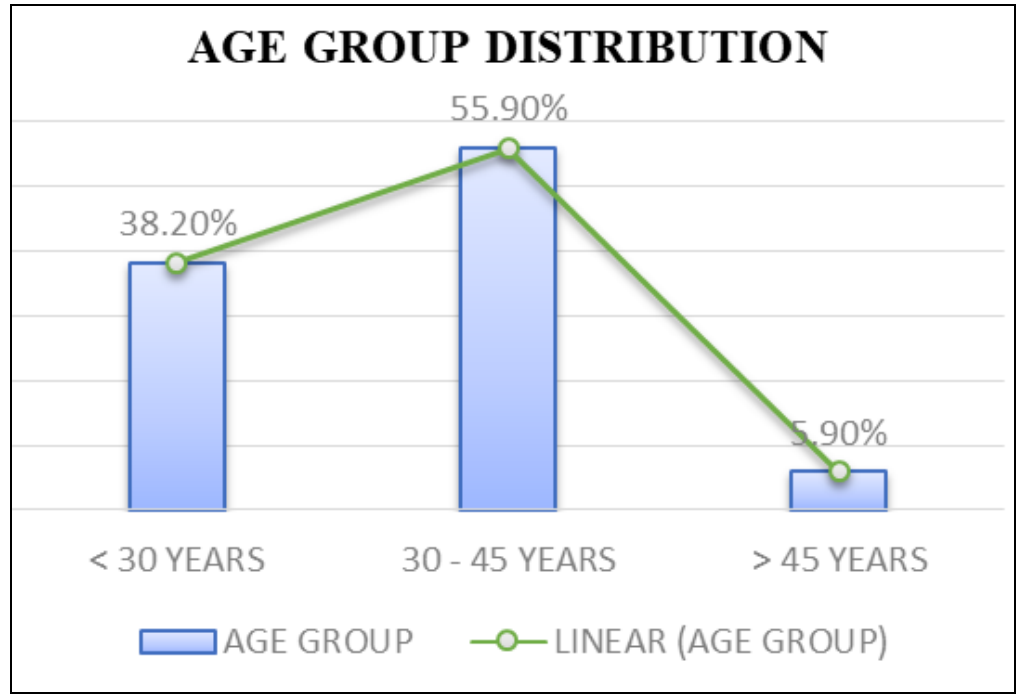

Fig 4: Age Group distribution

Forward Elevation (FE), Cross-Body Adduction (CBA), External Rotation with arm in adduction (ER1), External Rotation with arm in 90-degree abduction (ER2) and Internal 6 months follow up - Rotation (IR) movements were calculated pre-op, follow-ups at 1 month, 3 months and 6 months. There was a significant improvement post-surgery and explained in table 1. (Fig 5)

Table 1: Range of movements (Forward Elevation-FE, Cross-Body Adduction-CBA, External Rotation with arm in adduction-ER, External Rotation with arm in 90-degree abduction-ER2 and Internal Rotation-IR, SD-Standard deviation, Sig - Significant)

\begin{tabular}{|c|c|c|c|c|c|c|c|c|c|c|c|c|c|c|c|}
\hline \multirow{2}{*}{ Range of Movements } & \multicolumn{3}{|c|}{ FE } & \multicolumn{3}{|c|}{ CBA } & \multicolumn{3}{|c|}{ ER1 } & \multicolumn{3}{|c|}{ ER 2} & \multicolumn{3}{|c|}{ IR } \\
\hline & Mean & SD & p & Mean & SD & $\mathbf{P}$ & Mean & SD & $\mathbf{p}$ & Mean & SD & p & Mean & SD & p \\
\hline Pre-Op & 144.3 & 12.5 & & 45.4 & 4.6 & & 54.2 & 8.1 & & 75 & 3.6 & & 53.2 & 6.62 & \\
\hline Post OP 1 Month & 149.7 & 9.3 & Sig & 48.2 & 3.8 & Sig & 60.5 & 6 & Sig & 78.8 & 2.7 & Sig & 58.2 & 2.4 & Sig \\
\hline Post OP 3 Months & 151.1 & 6.4 & Sig & 50 & - & Sig & 65.8 & 4.3 & Sig & 88.2 & 7.1 & Sig & 66.3 & 2.5 & Sig \\
\hline Post OP 6 Months & 156.7 & 7.2 & Sig & 50 & - & Sig & 69.1 & 2.2 & Sig & 91.1 & 6.4 & Sig & 69.2 & 1.8 & Sig \\
\hline
\end{tabular}



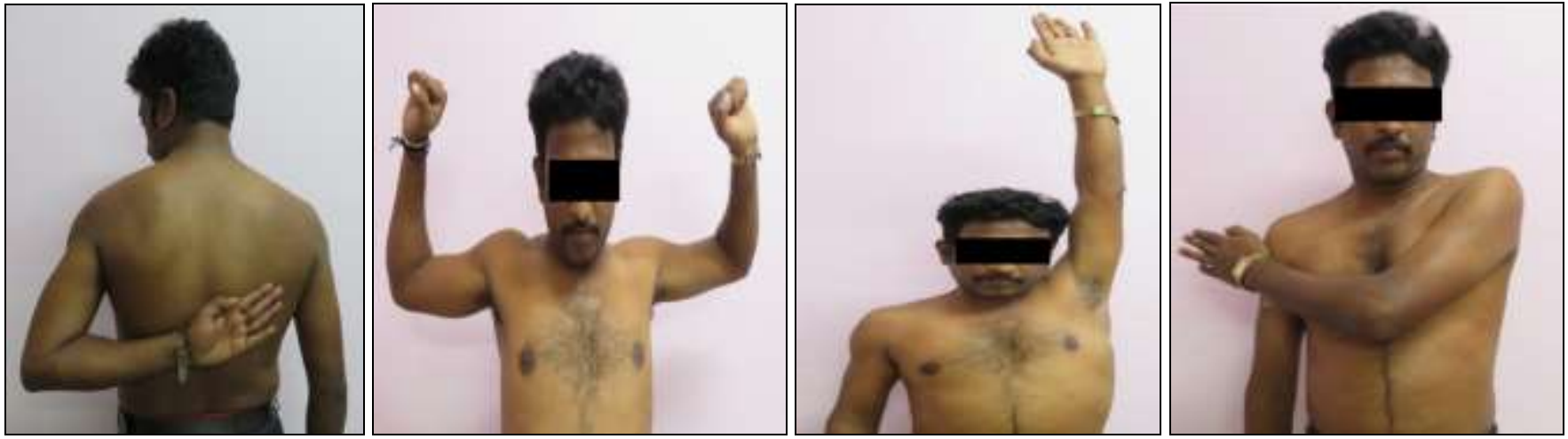

Fig 5: Range of movements - 6 months follow up

Mean VAS (Visual analogue scale) for pain among the patients in the study also reduced from pre-op value of 4.6 to 2.41, 1 and almost 0 at 1 month, 3 months and 6 months postop respectively and this reduction in pain was found to be highly significant. (Figure 6)

ROWE score which takes into account the stability, motion and function of the patient was found to have a highly significant improvement with follow ups at 1 month, 3 months and 6 months with scores of $53.68(+/-8.43), 68.59$ (+/- 6.83) and 90.59 (+/- 6.2.) respectively. Majority of the patients (N-31; 91.16\%) had excellent functional outcome and 3 patients $(8.82 \%)$ had fair outcome.

The American Shoulder and Elbow Surgeons (ASES) Shoulder Score which is both a physician-rated and patientrated scoring system showed a significant improvement at post-op follow ups. The post-op scores at 1 month, 3 months and 6 months were $67.8(+/-7.9), 80.8(+/-4.5)$, and $89.8(+/-$ 4.3) respectively. The mean pre-op ASES score was $47.5(+/-$ 6). (Figure 7).

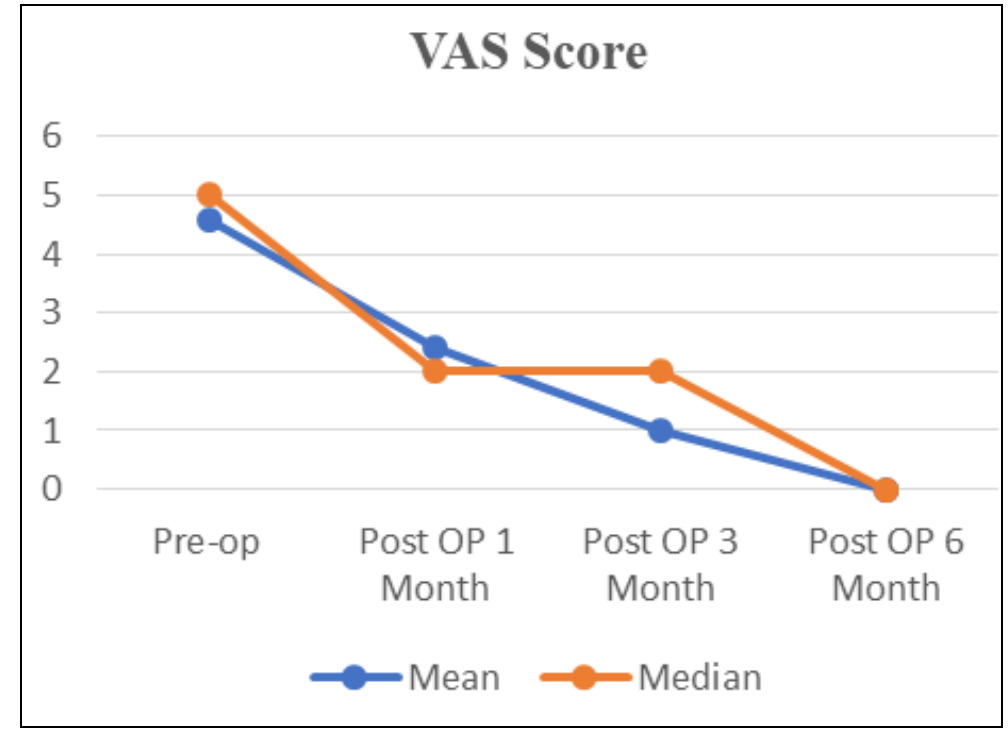

Fig 6: Visual Analogue Score

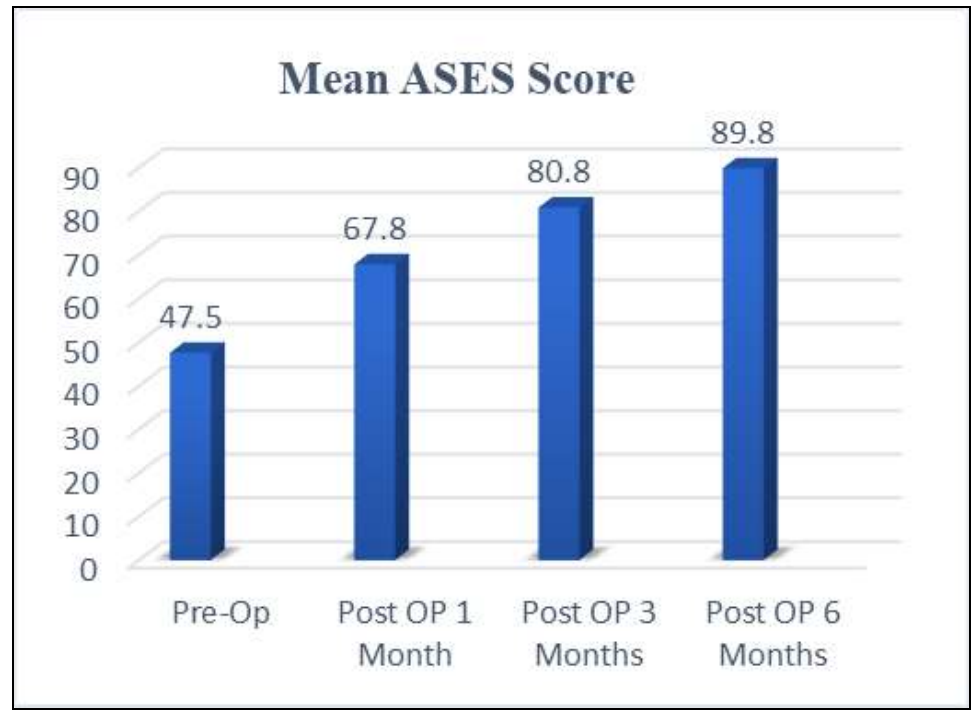

Fig 7: Mean ASES Score 
The Quick DASH (The Disabilities of Arm, Shoulder and Hand) score also showed good improvement in patient satisfaction and ROM, with postop scores at 1 month, 3 months and 6 months being $29.8(+/-7), 18.1$ (+/-6.3), and $10.5(+/-5.9)$ respectively. The mean pre-op Quick DASH score was $42.2(+/-8.6)$.

\section{Discussion}

Anterior glenohumeral dislocation followed by chronic anterior instability is the most common form of glenohumeral instability ${ }^{[15]}$. This is one of the most common situations in our orthopaedic practice. Rowe et al reported a $95.6 \%$ rate of anterior dislocation was caused due to trauma in their study of 500 patients ${ }^{[16]}$. Though the most common type of lesion involved is Bankart's lesion ${ }^{[17]}$. The prevalence of fracture or erosion of the glenoid rim in shoulders with recurrent anterior dislocation has been reported to range from $8 \%$ to $95 \%$ [18-29] and cases are on rise as time fleets due to recent enthusiasm for recreational and sporting activities, especially among young and active population.

The primary goal of any stabilisation procedure is to prevent recurrent instability with the goal of improving function, return to pre injury levels and to reduce long term sequelae. It is obvious that anatomic repair of the underlying pathology is the preferred procedure in anterior shoulder instabilities with Bankart lesion ${ }^{[30]}$. But, Bankart procedure is not the ideal surgery in conditions like contact or competitive sports athletes, significant bone loss or fracture of glenoid or humeral head, chronic erosion of glenoid rim, mid substance complete tear of glenohumeral ligament, humeral avulsion of glenohumeral ligament, deficient capsule, and complete radial tear of labrum ${ }^{[31-36]}$. So, bony procedures should be performed in these patients. Here in this study, we review our experience with one such bony procedure - Open Latarjet procedure in chronic anterior glenohumeral instability meeting our criteria which was originally described in 1954 . This short-term study highlights the importance of screening of patients for bone deficiency, treating them with open Latarjet procedure and evaluating their functional outcome.

Latarjet surgery is reported as good or excellent satisfied procedure in preventing the future instability because low post-operative recurrence rates of shoulder dislocation rates. According to Allain et al., in their 56 patients treated with an open Latarjet procedure for a mean of 14.3 years, none of them had a recurrent dislocation and only 1 patient reported a feeling of persistent instability and occasional subluxation ${ }^{[37]}$. Cassagnaud in his series of 106 Latarjet procedures with 7.5 years of follow up reported only one re-dislocation ${ }^{[38]}$. Whereas Collin in his 69 patients with mean follow up of 50 months had 4 recurrences and 2 subluxations ${ }^{[39]}$. According to Hovelius in his prospective study of 118 patients over 15 years follow up had subluxation in 11 and recurrences in 3 patients ${ }^{[40]}$. Our study similarly had no recurrences or redislocations post operatively. According to Banas et al., their cases showed $97 \%$ satisfaction during 8.6 years ${ }^{[41]}$. Hovelius et al. ${ }^{[40]}$ in their 15 years follow-up and Schroder et al. ${ }^{[42]}$ during 24.6 years showed 98 and $70 \%$ satisfaction, respectively. Most interestingly, Omidi-Kashani et al. [43] expressed $100 \%$ satisfaction in their study with mean follow up of 24.6 months which was in comparison with our study showing excellent satisfaction in about $91.16 \%$ and only 3 patients $(8.82 \%)$ had fair outcome with Rowe scores. Showing that the outcome of this study is not far from other studies. Though many studies have reported shoulder stiffness and significant loss of external rotation after this procedure ${ }^{[44,}$ $45,37,46]$ we did not encounter significant joint stiffness or limitation of external rotation. According to Hovelius et al ${ }^{[47]}$. there was $8^{\circ}$ mean loss of external rotation whereas Young and Walch ${ }^{[48]}$ did not find any significant loss of external rotation. With $9^{\circ}$ and $5^{\circ}$ mean reduction in external rotation by Banas et al. ${ }^{[41]}$ and Burkhart et al. ${ }^{[12]}$ respectively post operatively. All these were similar to our study with mean external rotation limitation was $5^{\circ}$ postoperatively without affecting the activities of their daily living. Moreover, this limitation can be corrected with proper rehabilitation protocols and regular follow up. Other complications encountered as neurologic injuries - such as Suprascapular, Axillary and Musculocutaneous nerve injuries, infections, post-operative arthritis, revision surgeries and complications related to screw such as - screw break down and non-union. Fortunately, our study did not have any of those complications. Minimally attributed to small group and shorter duration of study and follow up which can be considered as limitation of our study.

\section{Conclusion}

In conclusion, this study shows that Open Latarjet repair for anterior shoulder instability is a useful and successful procedure for patients with significant glenoid bone loss and heavy work demand such as contact athletes and manual labourers. Added to this even though Open Latarjet procedure is a non-anatomical repair it provides excellent functional results and patient satisfaction. Patient screening, identification and selection remains the key in determining the success of the repair and thus makes the patient to return to pre injury levels. Meticulous surgical technique and correct positioning of graft play a crucial role in determining the final functional outcome and thereby reducing the recurrences.

\section{Acknowledgments}

The authors would like to thank Dr. Chandrashekar and Dr. Prakashappa $\mathrm{T} \mathrm{H}$ for being supportive and encouraging us through the research.

\section{References}

1. Kazár B, Relovszky E. Prognosis of primary dislocation of the shoulder. Acta Orthop. 1969;40(2):216-224.

2. Hovelius L. Incidence of shoulder dislocation in Sweden. Clin Orthop Relat Res. 1982;166:127-131.

3. Boileau P, Villalba M, Hery JY, Balg F, Ahrens P, Neyton L. Risk factors for recurrence of shoulder instability after arthroscopic Bankart repair. J Bone Joint Surg Am 2006;88:1755-1763.

4. Burkhart SS, De Beer JF. Traumatic glenohumeral bone defects and their relationship to failure of arthroscopic Bankart repairs: significance of the inverted-pear glenoid and the humeral engaging Hill-Sachs lesion. Arthroscopy 2000;16:677-694.

5. Itoi E, Lee SB, Berglund LJ, Berge LL, An KN. The effect of a glenoid defect on anteroinferior stability of the shoulder after Bankart repair: a cadaveric study. J Bone Joint Surg Am 2000;82:35-46.

6. Owens BD, Agel J, Mountcastle SB, Cameron KL, Nelson BJ. Incidence of glenohumeral instability in collegiate athletics. Am J Sports Med 2009;37(9):1750-4.

7. Kaplan LD, Flanigan DC, Norwig J, Jost P, Bradley J. Prevalence and variance of shoulder injuries in elite collegiate football players. Am J Sports Med 2005;33 
(8):1142-6.

8. Charles Bessie`re, Christophe Trojani, Michel Carles Saurabh S, Mehta MS, Boileau. The Open Latarjet Procedure Is More Reliable in Terms of Shoulder Stability Than Arthroscopic Bankart Repair. Clin Orthop Relat Res DOI 10.1007/s11999-014-3550-9.

9. Mizuno N, Denard PJ, Raiss P, Melis B, Walch G. Longterm results of the Latarjet procedure for anterior instability of the shoulder. J Shoulder Elbow Surg 2014;23(11):1691-9.

10. Johanna Schulze-Borges, Dr. Eng, Jens D. Agneskirchner, Evgenij Bobrowitsch, Thilo Patzer, Melena Struck et al. Biomechanical Comparison of Open and Arthroscopic Latarjet Procedures. Arthroscopy : The journal of arthroscopic and related Surgery 2013;29(4):630-637.

11. Yiming Zhu, Chunyan Jiang, Guanyang Song. Investigation performed at the Shoulder Service, Beijing Ji Shui Tan Hospital, School of Medicine, Peking University, Beijing, China Arthroscopic Versus Open Latarjet in the Treatment of Recurrent Anterior Shoulder Dislocation With Marked Glenoid Bone Loss A Prospective Comparative Study. The American Journal of Sports Medicine, vol. XX, No.X,DOI : 10.1177/0363546517693845.

12. Burkhart SS, De Beer JF, Barth JR, Cresswell T, Roberts C, Richards DP. Results of modified Latarjet reconstruction in patients with anteroinferior instability and significant bone loss. Arthroscopy 2007;23:1033-41.

13. Booker S, Alfahad N, Scott M, Gooding B, Wallace WA. Use of scoring systems for assessing and reporting the outcome results from shoulder surgery and arthroplasty. World J Orthop 2015;6(2):244-51. doi: 10.5312/wjo.v6.i2.244. eCollection 2015 Mar 18.

14. Catherine J Fedorka, Mary K Mulcahey. Department of Orthopaedic Surgery, Hahnemann University Hospital/Drexel University College of Medicine, Philadelphia, PA, USA. Recurrent anterior shoulder instability: a review of the Latarjet procedure and its postoperative rehabilitation. Published in informa healthcare on, 2015.

15. Baker CL, Uribe JW, Whitman C. Arthroscopic evaluation of acute initial anterior shoulder dislocations. Am J Sports Med. 18(1):25-28.

16. Rowe CR, Zarins B. Recurrent transient subluxation of the shoulder. J Bone Jt Surg. 1978;63(6):863-872.

17. Erkoçak ÖF, Yel M. Bankart Repair with Knotless Anchors for Anterior Glenohumeral Instability. Eur J Gen Med 2010;7(2):179-186.

18. Henry JH, Genung JA. Natural history of glenohumeral dislocation: revisited. Am J Sports Med 1982;10:135137.

19. Hovelius L. Shoulder dislocation in Swedish ice hockey players. Am J Sports Med 1978;6:373-377.

20. Hovelius L, Eriksson K, Fredin H et al. Recurrences after initial dislocation of the shoulder: results of a prospective study of treatment. J Bone Joint Surg Am 1983;65:343349.

21. Kralinger FS, Golser K, Wischatta R, Wambacher M, Sperner G. Predicting recurrence after primary anterior shoulder dislocation. Am J Sports Med 2002;30:116-120.

22. Nobuhara K. The Shoulder: Its Function and Clinical Aspects [in Japanese]. 3rd ed. Tokyo, Japan: Igaku-shoin 2001.

23. Norlin R. Use of Mitek anchoring for Bankart repair: a comparable, randomized, prospective study with traditional bone sutures. J Shoulder Elbow Surg. 1994;3:381-385.

24. Rowe CR, Patel D, Southmayd WW. The Bankart procedure: a longterm end-result study. J Bone Joint Surg Am 1978;60:1-16.

25. Townley CO. The capsular mechanism in recurrent dislocation of the shoulder. J Bone Joint Surg Am 1950;32:370-380.

26. Matsen FA III, Thomas SC. Glenohumeral instability. In: Evarts CM, ed. Surgery of the Musculoskeletal System. 2nd ed. New York, NY: Churchill Livingstone 1990, 1439-1469.

27. Matsen FAIII, Thomas SC, Rockwood CA Jr, Wirth MA. Glenohumeral instability. In: Rockwood CA Jr, Matsen FA III, eds. The Shoulder. Philadelphia, Pa: WB Saunders; 1998;2:611-754.

28. Gill TJ, Micheli LJ, Gebhard F, Binder C. Bankart repair for anterior instability of the shoulder: long-term outcome. J Bone Joint Surg Am 1997;79:850-857.

29. Gill TJ, Zarins B. Open repairs for the treatment of anterior shoulder instability. Am J Sports Med. 2003;31:142-153.

30. Gill TJ, Zarins B. Open repairs for the treatment of anterior shoulder instability. Am J Sports Med. 2003;31:142-153.

31. Balg F, Boileau P. The instability severity index score. A simple pre-operative score to select patients for arthroscopic or open shoulder stabilisation. J Bone Joint Surg Br 2007;89:1470-1477.

32. Tjoumakaris FP, Abboud JA, Hasan SA et al Arthroscopic and open Bankart repairs provide similar outcomes. Clin Orthop Relat Res 2006;446:227-232.

33. Tauber M, Resch H, Forstner R et al. Reasons for failure after surgical repair of anterior shoulder instability. J Shoulder Elbow Surg 2004;13:279-285.

34. Mizuno N, Yoneda M, Hayashida K et al. Recurrent anterior shoulder dislocation caused by a midsubstance complete capsular tear. J Bone Joint Surg Am 2005;87:2717-2723

35. Bhagia SM, Ali MS. Bankart operation for recurrent anterior dislocation of the shoulder using suture anchor. Orthopedics 2000;23:589-591.

36. Lafosse L, Boyle S, Gutierrez-Aramberri $\mathrm{M}$ et al. Arthroscopic latarjet procedure. Orthop Clin North Am 2010;41:393-405.

37. Allain J, Goutallier D, Glorion C. Long-term results of the Latarjet procedure for the treatment of anterior instability of the shoulder. J Bone Joint Surg Am 1998;80:841-852.

38. Cassagnaud X, Maynou C, Mestdagh H. Clinical and computed tomography results of 106 Latarjet-Patte procedures at mean 7.5 year follow-up. Rev Chir Orthop Reparatrice Appar Mot 2003;89(8):683-692.

39. Collin P, Rochcongar P, Thomazeau H. Treatment of chronic anterior shoulder instability using a coracoid bone block (Latarjet procedure): 74 cases. Rev Chir Orthop Reparatrice Appar Mot 2007;93:126-132 (in French).

40. Hovelius L, Sandstrom B, Sundgren K, et al. One hundred eighteen Bristow-Latarjet repairs for recurrent anterior dislocation of the shoulder prospectively followed for fifteen years: Study I-clinical results. J Shoulder Elbow Surg 2004;13(5):509-516.

41. Banas MP, Dalldorf PG, Sebastianelli WJ et al Long- 
term followup of the modified Bristow procedure. Am J Sports Med 1993;21:666-671.

42. Schroder DT, Provencher MT, Mologne TS et al. The modified Bristow procedure for anterior shoulder instability: 26-year outcomes in Naval Academy midshipmen. Am J Sports Med 2006;34:778-786.

43. Omidi-Kashani F, Sadri-Mahvelati E, Mazlumi SM et al Is Bristow-Latarjet operation effective for every recurrent anterior shoulder dislocation? Arch Iran Med 2008;11:270-273.

44. Burkhart SS, De Beer JF, Barth JR, Cresswell T, Roberts C, Richards DP. Results of modified Latarjet reconstruction in patients with anteroinferior instability and significant bone loss. Arthroscopy 2007;23:1033-41.

45. Singer GC, Kirkland PM, Emery RJ. Coracoid transposition for recurrent anterior instability of the shoulder. A 20-year follow-up study. J Bone Joint Surg Br 1995;77:73-76.

46. Hovelius L, Vikerfors O, Olofsson A, et al. BristowLatarjet and Bankart: A comparative study of shoulder stabilization in 185 shoulders during a seventeen-year follow-up. J Shoulder Elbow Surg 2011;20(7):10951101.

47. Hovelius LK, Sandstro“m BC, Ro“smark DL et al. Longterm results with the Bankart and Bristow-Latarjet procedures: recurrent shoulder instability and arthropathy. J Shoulder Elbow Surg 2001;10:445-452.

48. Young A, Walch $\mathrm{G}$. Open bony augmentation of glenoid bone loss-the Latarjet and variants-surgical technique. In Provencher M, Romeo A, ed. Shoulder Instability: A comprehensive approach. Philadelphia: Elsevier Saunders 2011. 